\title{
ALGINATE MICROSPHERES CONTAINING CURCUMIN: PREPARATION, CHARACTERIZATION, AND IN VITRO HUMAN HAEMOGLOBIN GLYCOSYLATION ASSAY
}

\author{
KULKARNI AS*, BHUJBAL SS \\ Department of Pharmacognosy, Dr. D. Y. Patil Institute of Pharmaceutical Sciences and Research, Pune, Maharashtra, India. \\ Email: aditirjoshi2@gmail.com
}

Received: 26 April 2019, Revised and Accepted: 28 May 2019

\section{ABSTRACT}

Objective: The objective of the present study was to formulate, evaluate alginate microspheres of curcumin, and to investigate the inhibitory effect on glycosylated hemoglobin.

Methods: All formulations were prepared by an ionotropic gelation technique using sodium alginate as a polymer and calcium chloride as a crosslinker in varying concentrations. The formulation batches (F1-F6) were evaluated for physical properties such as compatibility studies, percentage entrapment efficiency (\%EE), microsphere yield, particle size, and polydispersity index. In vitro, drug release was studied and surface morphology was characterized by scanning electron microscopy.

Results: The microspheres showed \%EE, microsphere yield, particle size in the ranges of 44.86\%-84.24\%, 43.05\%-81.4\%, and 352-559 $\mu \mathrm{m}$, respectively. In vitro, drug release and release kinetics showed that the developed curcumin microspheres system is a promising delivery system for controlled drug release. Scanning electron micrographs indicate porous and rough surface. The inhibitory properties of curcumin and microspheres (F4) on glycosylation formation were investigated in hemoglobin using quercetin as standard. The decreased in hemoglobin concentration after incubation of hemoglobin with a graded concentration of glucose over a specified time was used as an index for in vitro human hemoglobin glycosylation assay. Glycosylation inhibition was about $75 \%$ for standard quercetin, $60 \%$ for curcumin microspheres, and $38.74 \%$ for curcumin suspension occurred after $72 \mathrm{~h}$.

Conclusion: From these results, it can be concluded that curcumin in microsphere formulation has better therapeutic potential and could prove to be useful in the development of antidiabetic formulation.

Keywords: Alginate microspheres, Hemoglobin, Glycosylation, Quercetin.

(c) 2019 The Authors. Published by Innovare Academic Sciences Pvt Ltd. This is an open access article under the CC BY license (http://creativecommons. org/licenses/by/4. 0/) DOI: http://dx.doi.org/10.22159/ajpcr.2019.v12i7.33770

\section{INTRODUCTION}

Glycosylation is a post-transitional modification of the protein, where sugar molecules covalently bound to free amino groups of protein residue. Glucose reacts, nonenzymatically with human hemoglobin to form amino-deoxy fructoseadducts, and initiate advanced glycation [1,2]. It was reported that such reactions take place both in vivo and in vitro. Non-enzymatic glycosylation of human hemoglobin leading to advanced glycation end products (AGEs) formation [3]. Maillard reaction indicates that reducing sugars react with amino acids, peptides, and proteins in solution producing dark-colored products. Thus, Maillard reaction results in some important, highly active intermediates such as Di-carbonyl products, glyoxal, and methylglyoxal [4]. The aldehyde functional group of sugars, non-enzymatically react with a thiol or amino groups of a protein (or another biomolecule) forming a Schiff base. Then, the Schiff bases rearrange to produce ketoamine or amadori products $[3,4]$. These amadori products undergo rearrangements and other reactions such as cyclization, oxidation, and dehydration to form more stable AGEs by both oxidative and non-oxidative pathways [5]. Impaired glucose metabolism is associated with oxidative stress. Under normal physiologic conditions also the formation of AGE takes place but is accelerated in hyperglycemia $[3,5]$.

Recent studies indicated that curcumin decreases blood glucose levels and glycated hemoglobin levels [6,7]. Curcumin is a yellow colored, hydrophobic polyphenolic pigment derived from rhizomes of Curcuma longa $\mathrm{L}$, belonging to the family, Zingiberaceae. C. longa $\mathrm{L}$. contains curcuminoids, thethree major components of curcuminoidsarecurcumin (77\%), demethoxycurcumin (17\%), and bisdemethoxycurcumin (3\%).
Curcumin is insoluble in water and ether but is soluble in ethanol, dimethylsulfoxide, and other organic solvents. Curcumin has been reported to play a beneficial role in various activities such as antioxidant, anti-inflammatory, antimicrobial, anticancer, antioxidant, antidiabetic, antihyperlipidemic, and hepatoprotective activity $[8,9]$. However, lowwater solubility, poor bioavailability, and rapid metabolism are major factors that limit the utility of curcumin [10]. Various formulations have been designed to improve the oral bioavailability of curcumin [11]. Sodium alginate has been widely used polymer for oral delivery because it is a biocompatible, biodegradable polymer, and minimal processing required for formulation development [12]

The purpose of the present study was to formulate curcumin microspheres and investigate its glycosylation inhibitory potential.

\section{MATERIALS AND METHODS}

The standard (quercetin) was purchased from Sigma-Aldrich, USA; curcumin purchased from Changsha Staherb Natural Ingredients Co., Ltd., China, other chemicals such as sodium alginate, calcium chloride, and polyethylene glycol 400 (PEG 400) were purchased from LOBA Chemie Pvt. Ltd. Mumbai.

\section{Compatibility study}

Fourier-transform infrared (FTIR) analyses of curcumin, sodium alginate, and their physical mixture were obtained using an FTIR spectrophotometer (Shimadzu R prestige-21 FTIR spectrophotometer). The pellets were prepared under hydraulic pressure of $150 \mathrm{~kg} / \mathrm{cm}^{2}$ on the KBr-press (Technosearch Instruments, Maharashtra, India); the 
spectra were scanned over 4000-400 $\mathrm{cm}^{-1}$ spectral range at ambient temperature.

\section{Preparation of curcumin-microspheres}

The curcumin microspheres were prepared by an ionic gelation technique which involves crosslinking in the presence of multivalent counterions. Curcumin was first triturated with PEG 400 and then entrapped in the polymer matrix of sodium alginate.

\section{Determination of microsphere yield}

It is expressed as a ratio of the total weight of microspheres to the total weight of all non-volatile ingredients including excipients used for the preparation of formulation. The microspheres in with particle size 371$559 \mu \mathrm{m}$ were used to determine percentage yield.

\section{Percentage entrapment efficiency (\%EE)}

Dried microspheres (100 mg) were ground in a mortar and then dispersed in ethanol. It was then sonicated for several hours to ensure exhaustive extraction of curcumin from microspheres. The resulting solution then filtered through $0.45 \mu \mathrm{m}$ membrane. Then, the absorbance of the resulting solution was taken at $424.5 \mathrm{~nm}$ with ultraviolet (UV)spectrophotometer (Shimadzu-UV-1800), and pure ethanol was used as blank.

$$
\% \mathrm{EE}=\frac{\text { Actual amount curcumin in microspheres }}{\text { Theoretical amount of curcumin }} \times 100
$$

\section{Particle size and polydispersity index (PDI)}

The particle size and PDI of formulation batches (F1-F6) were examined by a Zetasizer NanoZS90 (Malvern Instruments, Malvern, UK) at least three repetitions for each sample.

\section{Scanning electron microscopy (SEM)}

The microspheres were evaluated for surface and shape characteristics using SEM. The dry microspheres were randomly scanned and photomicrographs were taken on carbon stub coated with gold in an ion sputter Carl Zeiss Supra 5 model (Germany). The voltage provided was between 5 and $10 \mathrm{kV}$.

\section{In vitro dissolution studies}

To study in vitro drug release from microspheres, USP II dissolution apparatus was used. The test carried at $50 \mathrm{rpm}$ in the $900 \mathrm{ml}$ of $1 \mathrm{M}$ $\mathrm{HCl}(\mathrm{pH} \mathrm{1.2)}$ for $2 \mathrm{~h}$ followed by $900 \mathrm{ml}$ phosphate buffer ( $\mathrm{pH}$ 7.4) for $10 \mathrm{~h}$. The dissolution media were maintained at $37^{\circ} \mathrm{C} \pm 0.5^{\circ} \mathrm{C}$. Samples $5 \mathrm{ml}$ each were withdrawn at intervals and analyzed spectrometrically at $424.5 \mathrm{~nm}$. To maintain the sink condition, the release medium was replenished with the same amount of fresh medium.

\section{Statistical analysis}

To determine the kinetics of drug release from delivery systems, mathematical models were used. The obtained data were fitted to models such as zero-order, first-order, Higuchi, Korsmeyer-Peppas model, and Hixson's Crowell model [12,13].

\section{In vitro human hemoglobin glycosylation assay \\ Blood sample collection and preparation of hemoglobin}

Blood was collected from healthy donors after obtaining their consent. The samples were collected in ethylenediaminetetraacetic acid containing bottles. Preparation of hemolysate was based on the principle of hypotonic lysis [14]. As per the procedure [5], the blood was collected and then was washed with $0.14 \mathrm{M} \mathrm{NaCl}$ solution, thrice. Then, 1 volume of the suspension of red blood cells was lysed with 2 volumes of $0.01 \mathrm{M}$ phosphate buffer, $\mathrm{pH} 7.4$ and 0.5 volumes of carbon tetrachloride. The hemolysate was then centrifuged at $2300 \mathrm{rpm}$ for $15 \mathrm{~min}$ at room temperature so as to free it from the debris. The upper layer (hemoglobin rich fraction) was separated and stored into the sample bottle in the refrigerator at $-10^{\circ} \mathrm{C}$ until required for use.

\section{Estimation of hemoglobin glycosylation}

The hemoglobin concentrations were estimated by a reported method at $540 \mathrm{~nm}$ [15]. Non-enzymatic glycosylation inhibition was estimated according to the assay [16]. To $1 \mathrm{ml}$ of a solution of glucose (in $0.01 \mathrm{M}$ phosphate buffer pH7.4), $1 \mathrm{ml}$ hemoglobin fraction was added. The contents were kept incubated in the dark for $72 \mathrm{~h}$ at room temperature. The final concentrations of glucose were 2,10 , and $20 \mathrm{mg} / \mathrm{ml}$. This release hydroxyl-methyl-furfural and its estimation correspond to the degree of glycosylation. Blank solution where glucose was omitted, used as control.

Assay: Effect of curcumin and its formulation on hemoglobin glycosylation

In this experiment, the effect of quercetin (used as standard), suspension of curcumin and curcumin microparticles on hemoglobin glycosylation was tested. To $1 \mathrm{ml}$ of hemoglobin solution, $5 \mu \mathrm{l}$ of gentamycin, quercetin, suspension of curcumin, and its formulation in concentration $(50-1000 \mu \mathrm{g} / \mathrm{ml})$ was added. To this, $0.01 \mathrm{M}$ phosphate buffer $\mathrm{pH} 7.4$ and incubated in the dark at room temperature. The concentrations of glycated hemoglobin at the incubation period of 0 , 24 , and $72 \mathrm{~h}$ were estimated colorimetrically at $443 \mathrm{~nm}$ [5]. The test was conducted in triplicate.

\section{RESULTS AND DISCUSSION}

\section{FTIR spectroscopy}

FTIR spectrum of curcumin shows (Fig. 1) characteristic peaks at $803.42 / \mathrm{cm}, 1111.32 / \mathrm{cm}, 1275 / \mathrm{cm}, 1286.68 / \mathrm{cm}$, and $1687.68 / \mathrm{cm}$.
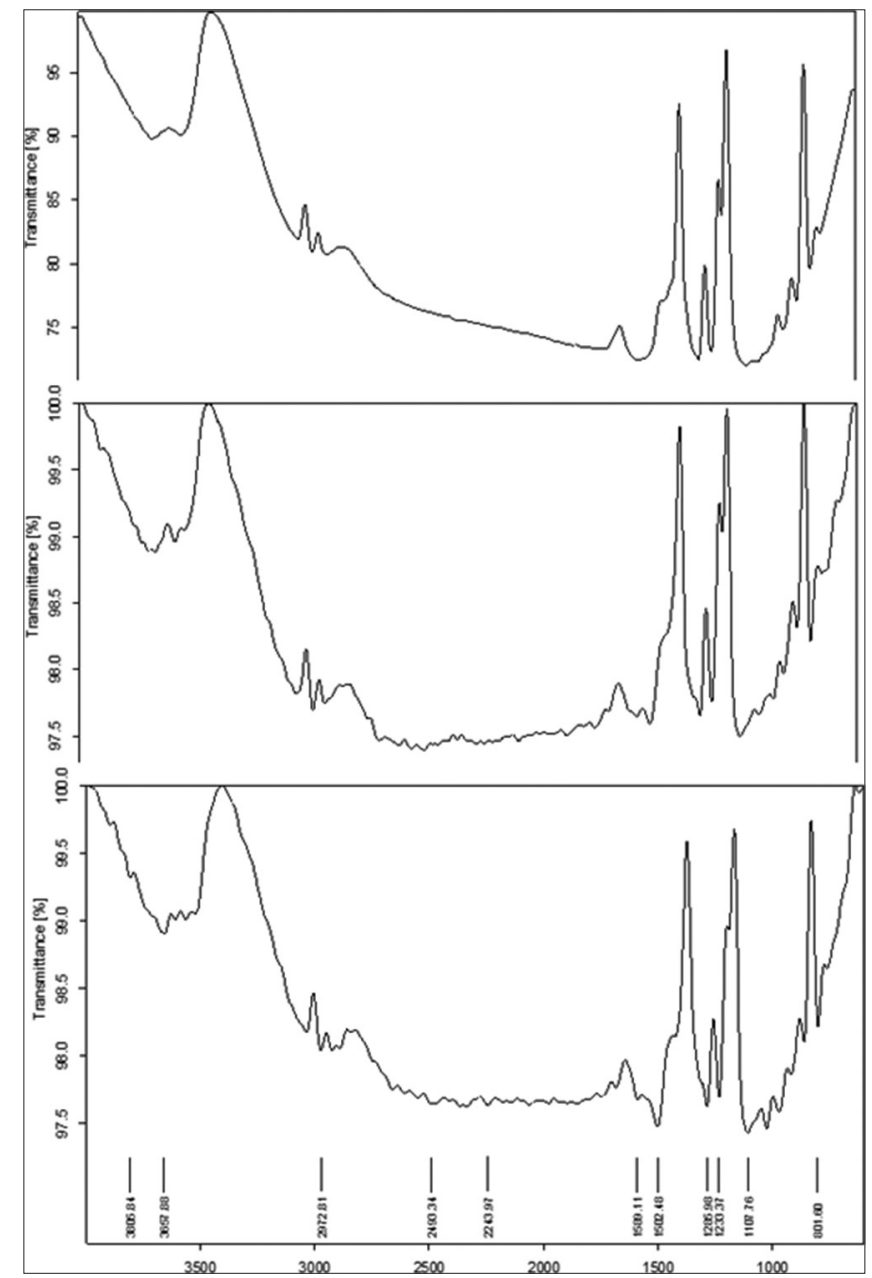

Fig. 1: Fourier-transform infrared spectra of sodium alginate, curcumin, and physical mixture 
The peak at $1687.68 / \mathrm{cm}$ is attributed to the enol group in curcumin. The strong and broad absorption peak at $3675.04 / \mathrm{cm}$ and $3550.34 / \mathrm{cm}$ due to stretching of $-\mathrm{OH}$ group in sodium alginate while stretching vibrations at $1287.24 / \mathrm{cm}, 1231.31 / \mathrm{cm}$, and $1081.23 / \mathrm{cm}$ due to $-\mathrm{C}-0$ and -C-O-C- groups of the polymer. However, the physical mixture of curcumin and sodium alginate retain their respective peaks indicating no physical interaction.

\section{SEM}

Scanning electron micrograph of batch F4 (Fig. 2) indicated that alginate microspheres are discrete and spherical in shape with rough surface morphology.

\section{$\% E E$, percentage yield, and particle size}

The percentage yield of microspheres was in the range of $43.05 \%-81.4 \%$. The percentage entrapment efficiency was found to be in the range of $57.18 \%-84.24 \%$ (Table 1). The concentration of sodium alginate and calcium chloride has an effect on percentage yield, percentage entrapment efficiency, and particle size. Increase in the concentration of sodium alginate increases percentage yield and percentage entrapment efficiency. However, manufacturing of microspheres became difficult as the concentration of alginate increases to $3 \%$ due to increase in viscosity [17]. At $2 \%$, the concentration of alginate fabrication of microspheres was smooth. Impact of concentration of crosslinker on particle size, entrapment efficiency, and percentage yield was observed. In the case of F3 and F4 formulations as a percentage of crosslinker increases yield and entrapment efficiency increases. This may be due to the availability of more $\mathrm{Ca}^{2+}$ ions with the carboxyl group of sodium alginate. In both F3 and F4 formulation, the increase in crosslinker concertation decreased in particle size was noted. Similar observations were made by Hariyadi et al. [17].

\section{In vitro release study}

All the batches were subjected to in vitro release study. Cumulative drug release after $12 \mathrm{~h}$ from different batches was shown in Fig. 3. The F3 and F4 showed sustained release pattern when compared with other batches. It can be seen from Fig. 3 that about 15\% drug release in acid pH 1.2 and about $85 \%$ drug release at pH 7.4. Fig. 3 also displayed the effect of polymer concentration and crosslinking on in vitro drug release, as polymer concentration increases drug release from polymer matrix found to be decreased. The formulation batches F5 and F6 with high polymer concertation show drug release up to $55 \%-60 \%$. The increased concentration of polymer may show increased swelling and decreases drug diffusion from the polymer matrix. Literature reported similar discussion [18]. Extend of crosslinking also affect drug release from formulation. As the concentration of crosslinker increases, retarded drug release was observed. This may be due to limitations in easy transport of drug molecule from polymer matrix [18,19]. Maximum release from microspheres was observed with phosphate buffer ( $\mathrm{pH} 7)$ as dissolution media. The release involves ion exchange between $\mathrm{Na}^{+}$ present in phosphate buffer and $\mathrm{Ca}^{2+}$ bound to carboxylic acid group of alginate. A higher percentage of crosslinker prolong the duration of ion exchange. Similarly, dense gel structure due to the high concentration of

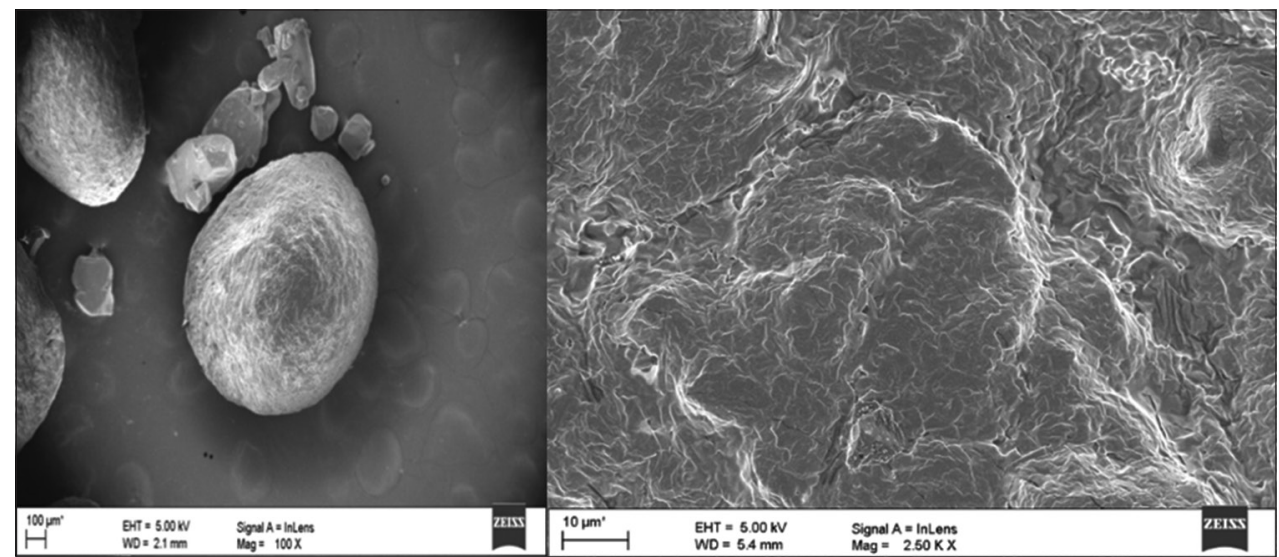

Fig. 2: Scanning electron micrograph of batch F4 microspheres and surface microstructures of prepared

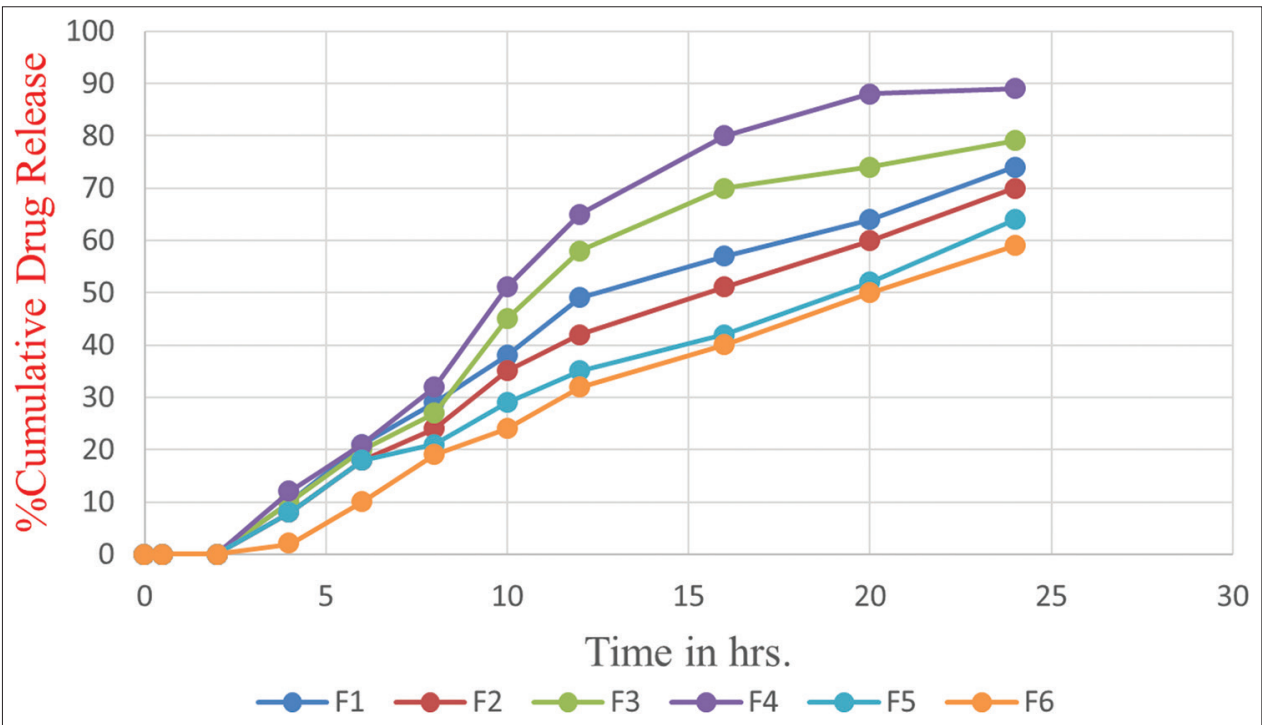

Fig. 3: Comparative percentage release of curcumin from formulation batches (F1-F6) 
Table 1: Formulation and characterization of batches F1-F6

\begin{tabular}{|c|c|c|c|c|c|c|}
\hline $\begin{array}{l}\text { Formulation } \\
\text { batches }\end{array}$ & $\begin{array}{l}\text { Amount of sodium } \\
\text { alginate }(\mathrm{g})\end{array}$ & $\begin{array}{l}\text { Amount of calcium } \\
\text { chloride (g) }\end{array}$ & $\% \mathrm{EE} \pm \mathrm{SD}$ & $\begin{array}{l}\text { Percentage } \\
\text { yield } \pm \text { SD }\end{array}$ & $\begin{array}{l}\begin{array}{l}\text { Particle } \\
\text { size }(\mu \mathrm{m}) \pm S D\end{array} \\
\end{array}$ & PDI \\
\hline F1 & 1 & 1 & $57.18 \pm 0.19$ & $43.05 \pm 3.67$ & $352.6 \pm 0.71$ & 0.659 \\
\hline F2 & 1 & 3 & $65.07 \pm 0.08$ & $48.3 \pm 1.14$ & $360 \pm 1.41$ & 0.803 \\
\hline F3 & 2 & 1 & $44.86 \pm 0.17$ & $57.8 \pm 4.9$ & $382.1 \pm 2.82$ & 0.847 \\
\hline F4 & 2 & 3 & $84.24 \pm 0.09$ & $81.4 \pm 3.95$ & $370.5 \pm 0.70$ & 0.415 \\
\hline F5 & 3 & 1 & $59.79 \pm 0.21$ & $64.2 \pm 4.24$ & $447.5 \pm 1.14$ & 0.771 \\
\hline F6 & 3 & 3 & $52.81 \pm 0.11$ & $69.25 \pm 2.89$ & $559 \pm 2.82$ & 0.902 \\
\hline
\end{tabular}

\%EE: Percentage entrapment efficiency, SD: Standard deviation, PDI: Polydispersity index

Table 2: Kinetic values of formulation F4

\begin{tabular}{lllllll}
\hline Batch code & Zero-order $\boldsymbol{R}^{2}$ & First-order $\boldsymbol{R}^{2}$ & Higuchi model $\boldsymbol{R}^{2}$ & \multicolumn{2}{c}{ Korsmeyer-Peppas model } \\
\cline { 3 - 5 } & & & $\boldsymbol{R}^{\mathbf{2}}$ & \multicolumn{2}{c}{ Hixson's-Crowell model $\boldsymbol{R}^{\mathbf{2}}$} \\
\hline F4 & 0.9841 & 0.0264 & 0.9717 & 0.9519 & 1.33 \\
\hline
\end{tabular}

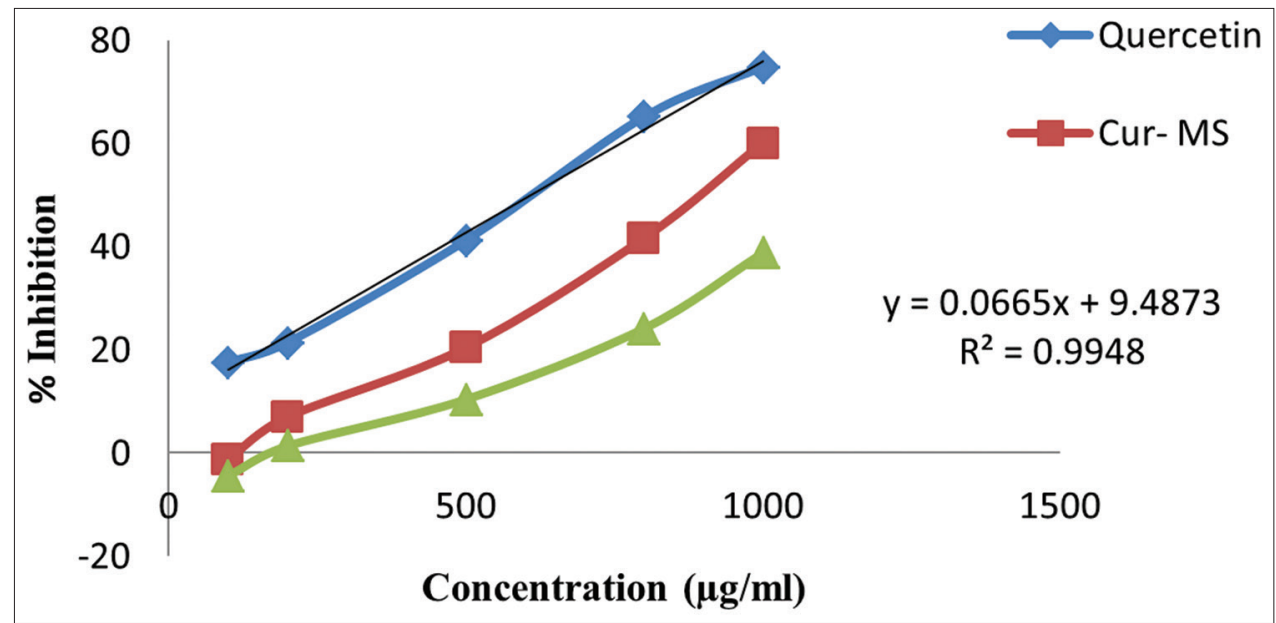

Fig. 4: Comparative effects of varying concentration of quercetin, curcumin, and formulation on non-enzymatic human hemoglobin glycosylation after $72 \mathrm{~h}$

sodium alginate may restrict diffusion and delay ion exchange process. Similar observations have been made by Voo et al. where the effect of polymer and crosslinker on dissolution was studied [19].

On the basis of percentage yield, entrapment efficiency, and particle size F4 batch was found to be optimum and was further characterized for the study of release kinetics. In all the cases, the best-fit model was found to be Korsmeyer-Peppas with "n" value between $n>0.85$ (Table 2) suggesting super Case II transport mechanism, i.e., erosion of the polymeric chain stresses hydrophilic polymers which swell in water, followed by diffusion controlled release zero-order mechanism. The results were in agreement with a study conducted by Mazumder et al. [20].

\section{In vitro human hemoglobin glycosylation assay}

The results of glycosylation assay suggest that curcumin inhibits binding of glucose to hemoglobin. Glucose non-enzymatically reacts with human hemoglobin components forming glycosylated hemoglobin [2]. Glycation of proteins results in formation of o advanced glycation end products (AGEs) due to intermolecular rearrangements. Theses AGEs are responsible for diabetic complications [3]. This inhibition of glycosylation by adjuvant therapy could delay the onset of diabetic complications [5]. Curcumin has been screened for its antioxidant and antidiabetic effect [6]. In the present study, therefore, the effect of curcumin and its microspheres on hemoglobin glycosylation was evaluated. Experiments were designed to investigate the effect of graded concentration of curcumin and its formulation on hemoglobin glycosylation at varying periods of incubation (24-72 h). The data revealed that [Fig. 4] maximum inhibition up to $75 \%$ (standard quercetin), 60\% (curcumin microspheres), and 38.74\% (curcumin suspension) occurred after $72 \mathrm{~h}$ of incubation. Curcumin microspheres demonstrated better performance in comparison with curcumin.

\section{CONCLUSION}

In this study, curcumin microspheres were successfully developed using the ionic gelation technique. The entrapment efficiency, yield, and drug release were influenced by sodium alginate and calcium chloride concentrations. Administration of curcumin inhibits glycosylation of hemoglobin. Together our, data suggest that curcumin microspheres may be more effectively utilize curcumin in therapeutic applications.

\section{ACKNOWLEDGMENTS}

The authors greatly acknowledge for Pharmaceutics and Biochemistry Department, Dr. D. Y. Patil Institute of Pharmaceutical Science and Research for excellent technical assistance.

\section{AUTHORS' CONTRIBUTIONS}

Aditi S. Kulkarni as author carried out the experimental work, data collection, data analysis, and manuscript drafting. Dr. S. S. Bhujbal is principal advisor involved in designing of work, data interpretation, and provided resources for research work. 


\section{CONFLICTS OF INTEREST}

No conflicts of interest associated with this work.

\section{REFERENCES}

1. Peacock I. Glycosylated haemoglobin: Measurement and clinical use. J Clin Pathol 1984;37:841-51.

2. Shapiro R, McManus MJ, Zalut C, Bunn HF. Sites of nonenzymatic glycosylation of human hemoglobin A. J Biol Chem 1980;255:3120-7.

3. Nawale RB, Mourya VK, Bhise SB. Non-enzymatic glycation of proteins: A cause for complications in diabetes. Indian $\mathrm{J}$ Biochem Biophys 2006;43:337-44.

4. Thorpe SR, Baynes JW. Maillard reaction products in tissue proteins: New products and new perspectives. Amino Acids 2003;25:275-81.

5. Adisa RA, Oke J, Olomu SA, Olorunsogo O. Inhibition of human haemoglobin glycosylation by flavonoid containing leaf extract of Cnestis ferruginea. J Cameroon Acad Sci 2004;4:351-9.

6. Arun N, Nalini N. Efficacy of turmeric on blood sugar and polyol pathway in diabetic albino rats. Plant Foods Hum Nutr 2002;57:41-52.

7. Seo KI, Choi MS, Jung UJ, Kim HJ, Yeo J, Jeon SM, et al. Effect of curcumin supplementation on blood glucose, plasma insulin, and glucose homeostasis related enzyme activities in diabetic $\mathrm{db} / \mathrm{db}$ mice. Mol Nutr Food Res 2008;52:995-1004.

8. Duggi S, Handral HK, Handral RA, Tulsianand G, Shruthi SD. Turmeric: Nature's precious medicine. Asian J Pharm Clin Res 2013;6:10-6.

9. Purpura M, Lowery RP, Wilson JM, Mannan H, Münch G, RazmovskiNaumovski V. Analysis of different innovative formulations of curcumin for improved relative oral bioavailability in human subjects. Eur J Nutr 2018;57:929-38.

10. Anand P, Kunnumakkara AB, Newman RA, Aggarwal BB. Bioavailability of curcumin: Problems and promises. Mol Pharm 2007;4:807-18.
11. Wang S, Tan M, Zhong Z, Chen M, Wang Y. Nanotechnologies for curcumin: An ancient puzzler meets modern solutions. J Nanomater 2011;2011:1-8

12. Szekalska M, Pucilowska A, Szymanska E, Ciosek P, Winnicka K. Alginate: Current use and future perspectives in pharmaceutical and biomedical applications. Int J Polym Sci 2016;2016:1-17.

13. Dash S, Murthy PN, Nath L, Chowdhury P. Kinetic modeling on drug release from controlled drug delivery systems. Acta Pol Pharm 2010;67:217-23

14. Asgary S, Naderi G, Sarrafzadegan N, Ghassemi N, Boshtam M, Rafie M, et al. Anti-oxidant effect of flavonoids on hemoglobin glycosylation. Pharm Acta Helv 1999;73:223-6.

15. Drabkin DL, Austin JH. Spectrophotomeric studies: Spectrophotometric constant for common hemoglobin derivatives in human, dogs and rabbit blood. J Biol Chem 1932;98:719.

16. Parker KM, England JD, Da Costa J, Hess RL, Goldstein DE. Improved colorimetric assay for glycosylated hemoglobin. Clin Chem 1981;27:669-72.

17. Hariyadi DM, Hendradi E, Purwanti T, Fadil F, Ramadani C. Effect of cross linking agent and polymer on the characteristics of ovalbumin loaded alginate microspheres. Int J Pharm Pharm Sci 2014;6:469-74.

18. Madhavi C, Kumara Babu P, Maruthi Y, Parandhama A, Shreenath Reddy O, Rao KC, et al. Sodium alginate - Locust bean gum ipn hydrogel beads for the controlled delivery of nimesulide-antiinflammatory drug. Int J Pharm Pharm Sci 2017;9:245-52.

19. Voo WP, Chien CW, Islam A, Tey BT, Chan ES. Calcium alginate hydrogel beads with high stiffness and extended dissolution behaviour. Eur Polym J 2016;75:343-53.

20. Mazumder R, Nath K, Haque A, Maity T, Choudhury PK, Shrestha B, et al. Formulation and in vitro evaluation of natural polymers based microspheres for colonic drug delivery. Int J Pharm Pharm Sci 2010;2:211-9. 